\title{
Sexual dimorphism of invasive knifefish (Chitala ornata) in Laguna de bay, Philippines
}

\author{
Jhon Michael C. Castro ${ }^{1^{*}}$, Jon Carlo B. Gonzales ${ }^{2}$, and Ma. Vivian C. Camacho ${ }^{1,2}$
}

\begin{abstract}
Chitala ornata (J.E. Gray) (Osteoglossiformes: Notopteridae) has since established abundant and nuisance populations in Laguna de Bay. A fundamental prerequisite for the development of management strategies for invasive species like $C$. ornata is a full understanding of its life history characteristics including sexual dimorphism. In the present study, we examined the sexual dimorphism of $C$. ornata. Sexes of $C$. ornata can be distinguished through the examination of its genital papilla wherein females show distinct morphological adaptions for effective oviposition on a spawning substrate. Comparison of means and multivariate analysis of several morphometric characters showed that sexual size dimorphism in $C$. ornata is female-biased which is mainly attributed to the disparity of resource expenditure between sexes for reproduction and size-dependent advantages of females in the production of more progenies with better chances of survival.
\end{abstract}

Keywords: genital papilla, invasive species, Principal Component Analysis, sexual size dimorphism, teleost

\section{Introduction}

Sexual dimorphism, or phenotypic divergence between the sexes, is a common and often substantial form of intraspecific phenotypic variation in sexually reproducing species (McGee and Wainwright, 2013). The most typical example are the differences in characteristics of reproductive organs. Other possible examples are for secondary sex characteristics like body size, ornamentation, behavior, and other bodily traits (Esmaeili et al., 2017). The evolution of secondary sexual characteristics is usually the result of a disparity in the investment of males and females towards successful production of viable progenies (Andersson, 1994). Such characteristics play an important role in the establishment and subsequent dominance of invasive species in a novel environment (Grabowska \& Przybylski, 2015), like in the case of invasion of the knifefish, Chitala ornata (Gray, 1831) in Laguna de Bay, Philippines.

\footnotetext{
${ }^{1}$ Animal Biology Division, Institute of Biological Sciences, College of Arts and Sciences, University of the Philippines-Los Baños, College, Laguna 4031, Philippines

${ }^{2}$ Limnological Station, University of the Philippines-Los Baños, College, Laguna 4031, Philippines
}

*Corresponding email: jccastro5@up.edu.ph

Date Submitted: 25 April 2019

Date Accepted: 15 April 2020
Chitala ornata is a carnivorous fish that is indigenous to the Mekong River (Poulsen \& Valbo-Jørgensen, 2000). It was introduced in the Philippines primarily for ornamental purposes (Cagauan, 2007), however for yet undetermined reason(s) some individuals have found their way in Laguna de Bay and established its population there. It is considered a nuisance species in Laguna de Bay because it voraciously feeds on endemic and aquaculture fish species of the lake. Aspects of the reproductive biology of $C$. ornata in Laguna de Bay has been previously studied by Castro et al. (2018).

A better understanding of the life history of an invasive species, specially those aspects that contribute most to its population growth including sexual dimorphism, is necessary to attain control over its population (Loppnow et al., 2013). Here the sexual dimorphism of $C$. ornata was assessed specifically examining the variations in the external morphology of genital papillae and several morphometric characters between sexes.

\section{Materials and Methods}

\section{Study Area}

The present study was conducted in Laguna de Bay, also known as Laguna Lake (Fig. 1). It occupies an area approximately $900 \mathrm{~km}^{2}$ with a shoreline of $220 \mathrm{~km}$. It has an average depth of $2.5 \mathrm{~m}$ and a maximum water holding capacity of 2.9 billion $\mathrm{m}^{3}$. A more detailed description of the study site is available in Castro et al. (2018). 


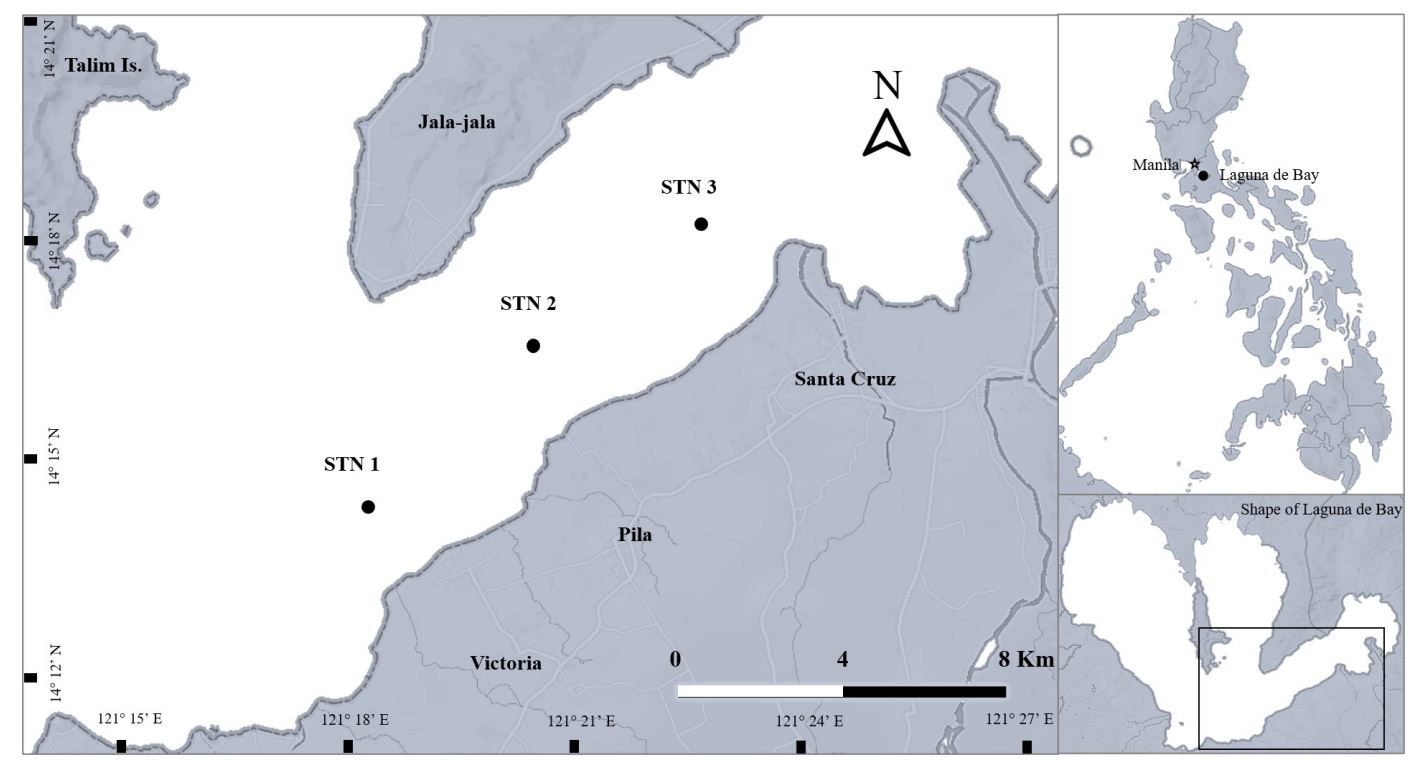

Figure 1. Sampling sites (filled circles, STN1 - STN3) for Chitala ornata in the East bay of Laguna de Bay.

\section{Fish Sampling and Data Collection}

From May 2015 to April 2016, mature knifefish samples were collected monthly using drag seine net with stretched mesh size of $20 \mathrm{~cm}$ in three sites located in East bay of Laguna de Bay. Four nets were deployed per site and per month from 4:00 to 6:00 a.m. All knifefish caught in the net were collected and processed within $24 \mathrm{~h}$. A total of eighteen (18) morphometric characters were measured on the left side of each individual: total length (TL), standard length (SL), trunk length (TrL), head length (HL), prepectoral fin length (PrePcFL), predorsal fin length (PreDFL), postdorsal fin length (PostDFL), head depth (HD), body depth at anus (BDA), body depth at dorsal fin (BDDF), eye diameter (ED), pre-orbital length (PreOL), post-orbital length (PostOL), pectoral base fin length (PcBFL), pectoral fin length (PcFL), dorsal base fin length (DBFL), dorsal fin length (DFL) and anal fin length (AFL). Measurements were determined using Image $\mathrm{J}$ which utilized calibrated photographs of the left side of each specimen taken by a digital single lensed reflex camera. The sex of each specimen was confirmed by inspection of dissected gonads while macroscopic characteristics (modified from BrownPeterson et al., 2011) were used to determine gonad maturity stage. General morphology (i.e., coloration, position size and shape) of genital papillae of 20 mature individuals for each sex was observed.

\section{Data Analysis}

Mean lengths relative to total length of each metric variable between sexes were compared using Student's t-test $(\mathrm{P}<0.05)$ to determine those morphometric characters differing significantly between sexes. Principal Component Analyses (PCA) was utilized to identify the variables that contribute the most to the differences and to compare overall patterns of sexual size dimorphism in knifefish.

\section{Results and Discussion}

\section{Urogenital Papilla}

Observations showed first recorded variation in the genital papillae between male and female knifefish. The genital papilla of female knifefish (Fig. 2a) is an elongated pale yellow to white tube with an opening directed towards the anterior and is equivalent to, or wider than, that of the anal opening. It is accompanied by a posteriorly located basal platform which is the swollen tissue immediately posterior to the base of the genital papilla (Martin \& Page, 2015). Male knifefish (Fig. 2b) have short blunt dark brown to red genital papillae. The downward facing opening is narrower than that of the anal opening.

Egg-attaching species, including knifefish, possess almost exclusively tubular papillae. Martin \& Page (2015) described the papilla as elongate, cylindrical to conical that projected from the ventral surface of the body. The interaction between the genital papilla and an oviposition substrate may determine the survivability of an egg. Genital papillar morphology may be indicative of how effectively a fish deposits eggs on a specific substrate. For example, when the papilla is extremely swollen during the spawning season, the basal platform may be particularly helpful in propping a papilla downward, away from the body (Martin \& Page, 2015). The basal platform may 


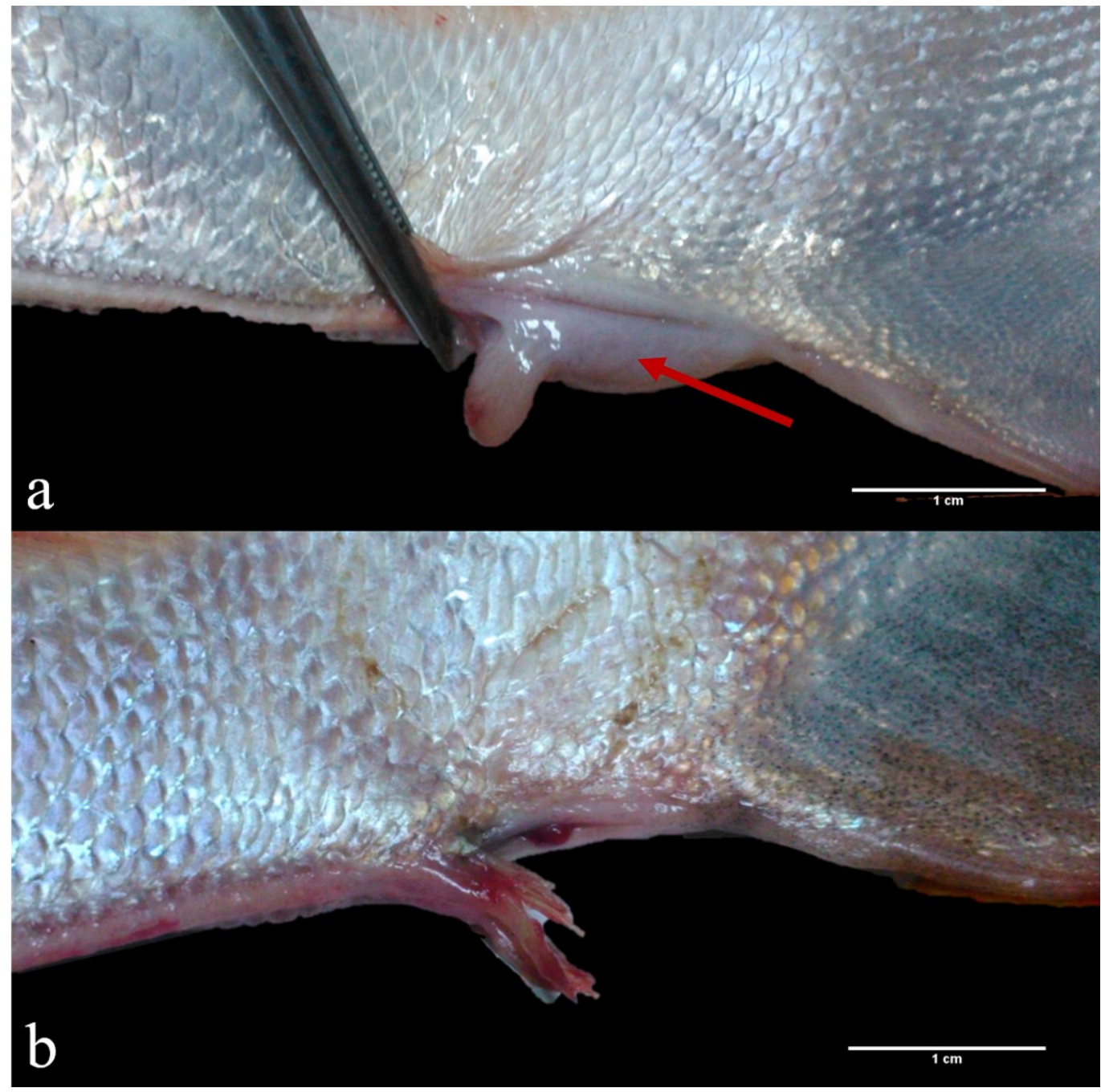

Figure 2. Urogenital papillae of (a) female with anal fin retracted and (b) male Chitala ornata from Laguna de Bay. Arrow indicates basal platform in female genital papilla.

contribute to precise oviposition on a substrate (Martin \& Page, 2015).

\section{Sexual Size Dimorphism}

A total of 192 matured knifefish individuals were collected, of which 55 were female and 137 were male or an overall ratio of 1:2.49, respectively. Mean lengths of each metric variable relative to total length were compared between sexes. Student's t-test $(\mathrm{P}<0.05)$ showed that sexes varied significantly body depth at anus (BDA, Table 1). Significant larger values for BDA among female individuals can be due to increasing volume of eggs prior to spawning.

PCA of metric variables revealed that the first two principal components contributed $90.34 \%$ of the total variance (Fig. 3). Principal Component 1 (PC1) elucidated 85.83\% variance and was mostly accounted for by AFL and body size characters like TL, SL, TrL, PreDFL, and PostDFL (Fig. 4). PCA showed that sexual size dimorphism in C. ornata is female -biased wherein morphometric characters measured were consistently greater in female individuals than their male counterparts. This result is in contrast with a fundamental allometric relationship called Rensch's rule (Rensch, 1950). It states that sexual size dimorphism increases with body size when males are larger than females, whereas size dimorphism decreases with increasing body size when females are larger. In the present study although female knifefish were consistently larger than males, the score distribution of male and female metric variables showed distinct clustering and no overlapping. This suggests that metric characters are highly conserved and that sexes are distinctly dimorphic. This observation in knifefish contradictory to Rensch's rule mirrored the results of Webb \& Freckleton (2007) analysis of 1291 species of birds across 30 
Table 1. Summary (range; mean \pm standard deviation (SD)) and comparison of mean values of morphometric variables in relation of total length of male and female Chitala ornata from Laguna de Bay.

\begin{tabular}{|c|c|c|c|c|}
\hline \multirow{2}{*}{$\begin{array}{c}\text { Metric Variables } \\
\text { (in \% TL) }\end{array}$} & \multicolumn{2}{|c|}{ Male $n=137$} & \multicolumn{2}{|c|}{ Female $n=55$} \\
\hline & Range & Mean \pm SD & Range & $\operatorname{Mean} \pm \mathbf{S D}$ \\
\hline SL & $92.41-96.19$ & $94.34 \pm 1.11$ & $91.79-96.22$ & $94.58 \pm 0.83$ \\
\hline $\operatorname{TrL}$ & $76.66-86.24$ & $79.86 \pm 1.35$ & $74.87-85.92$ & $79.42 \pm 7.35$ \\
\hline PrePcFL & $16.07-21.90$ & $18.66 \pm 1.19$ & $15.56-20.86$ & $18.72 \pm 1.10$ \\
\hline HL & $12.63-17.13$ & $14.58 \pm 0.94$ & $11.77-16.83$ & $14.37 \pm 0.93$ \\
\hline $\mathrm{HD}$ & $16.47-21.86$ & $18.66 \pm 1.34$ & $15.14-22.32$ & $18.41 \pm 1.37$ \\
\hline BDA* & $24.43-29.67$ & $26.70 \pm 1.83$ & $24.91-32.75$ & $27.25 \pm 1.43$ \\
\hline BDDF & $22.20-27.37$ & $24.23 \pm 0.98$ & $22.48-27.94$ & $24.16 \pm 0.99$ \\
\hline PreDFL & $35.35-56.27$ & $51.96 \pm 2.20$ & $49.96-57.13$ & $52.45 \pm 1.52$ \\
\hline PostDFL & $50.64-59.56$ & $55.05 \pm 2.26$ & $52.80-60.57$ & $55.62 \pm 1.57$ \\
\hline PcBFL & $2.00-3.57$ & $2.72 \pm 0.91$ & $1.84-3.29$ & $2.64 \pm 0.30$ \\
\hline PcFL & $11.15-16.87$ & $13.35 \pm 0.93$ & $11.41-15.93$ & $13.19 \pm 0.95$ \\
\hline DBFL & $2.11-4.55$ & $3.09 \pm 0.37$ & $2.27-3.89$ & $3.17 \pm 0.37$ \\
\hline DFL & $7.47-14.41$ & $11.26 \pm 1.35$ & $7.35-14.04$ & $11.10 \pm 1.58$ \\
\hline AFL & $69.27-98.60$ & $73.68 \pm 4.65$ & $67.37-78.62$ & $73.50 \pm 2.51$ \\
\hline ED & $1.25-2.90$ & $2.02 \pm 0.30$ & $1.27-3.62$ & $1.97 \pm 0.38$ \\
\hline PreOL & $1.27-3.43$ & $2.27 \pm 0.38$ & $1.53-2.75$ & $2.47 \pm 1.85$ \\
\hline PostOL & $9.06-15.00$ & $11.43 \pm 1.16$ & $1.90-14.05$ & $11.15 \pm 2.06$ \\
\hline
\end{tabular}




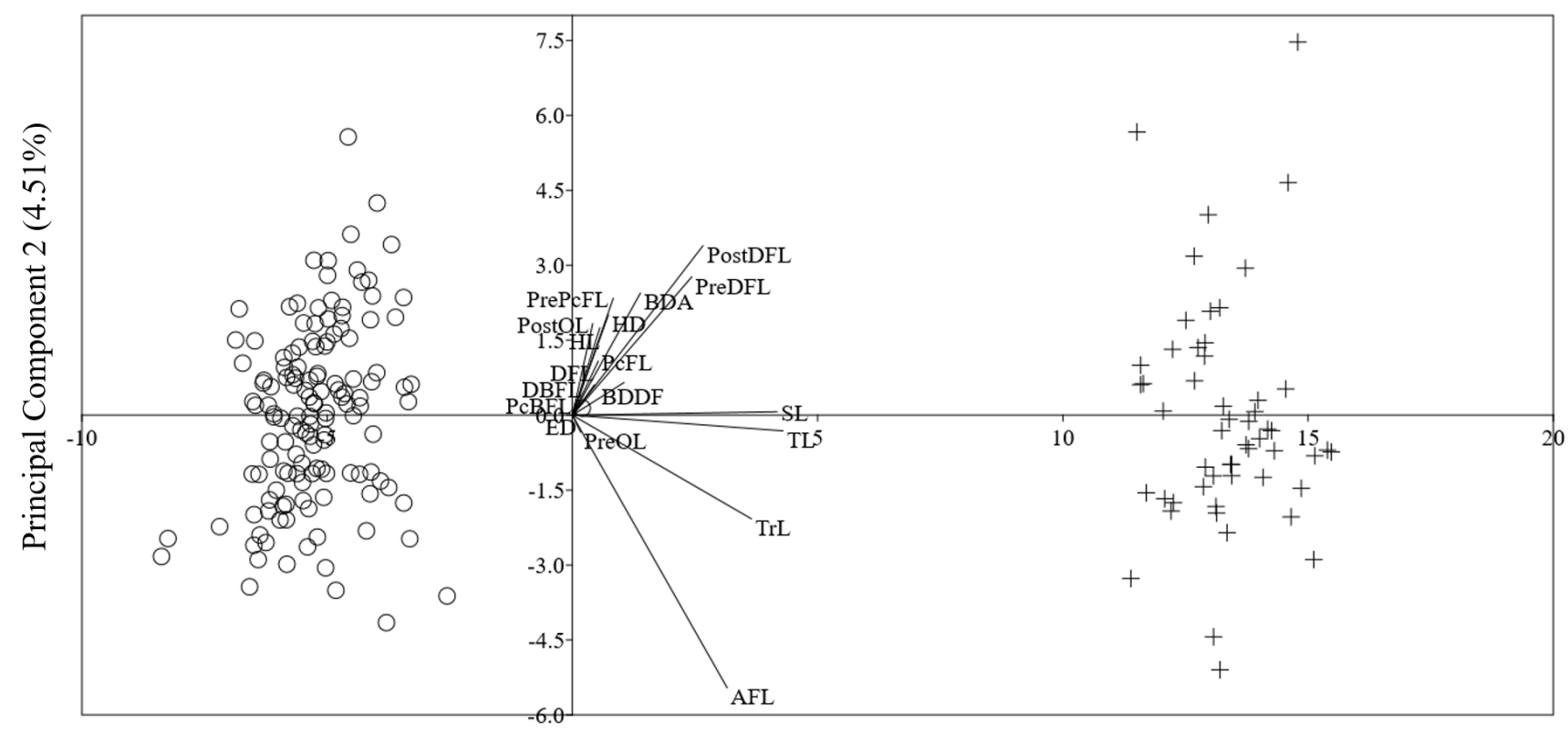

Principal Component 1 (85.83\%)

Figure 3. Scatter biplot score on the first two principal components for size-adjusted metric characters obtained from male and female Chitala ornata collected from Laguna de Bay. Female $+(n=55)$; male $\circ(n=137)$. Plotted line with corresponding metric variable denotes \% variance contributed in both $\mathrm{PC} 1$ and $\mathrm{PC} 2$.

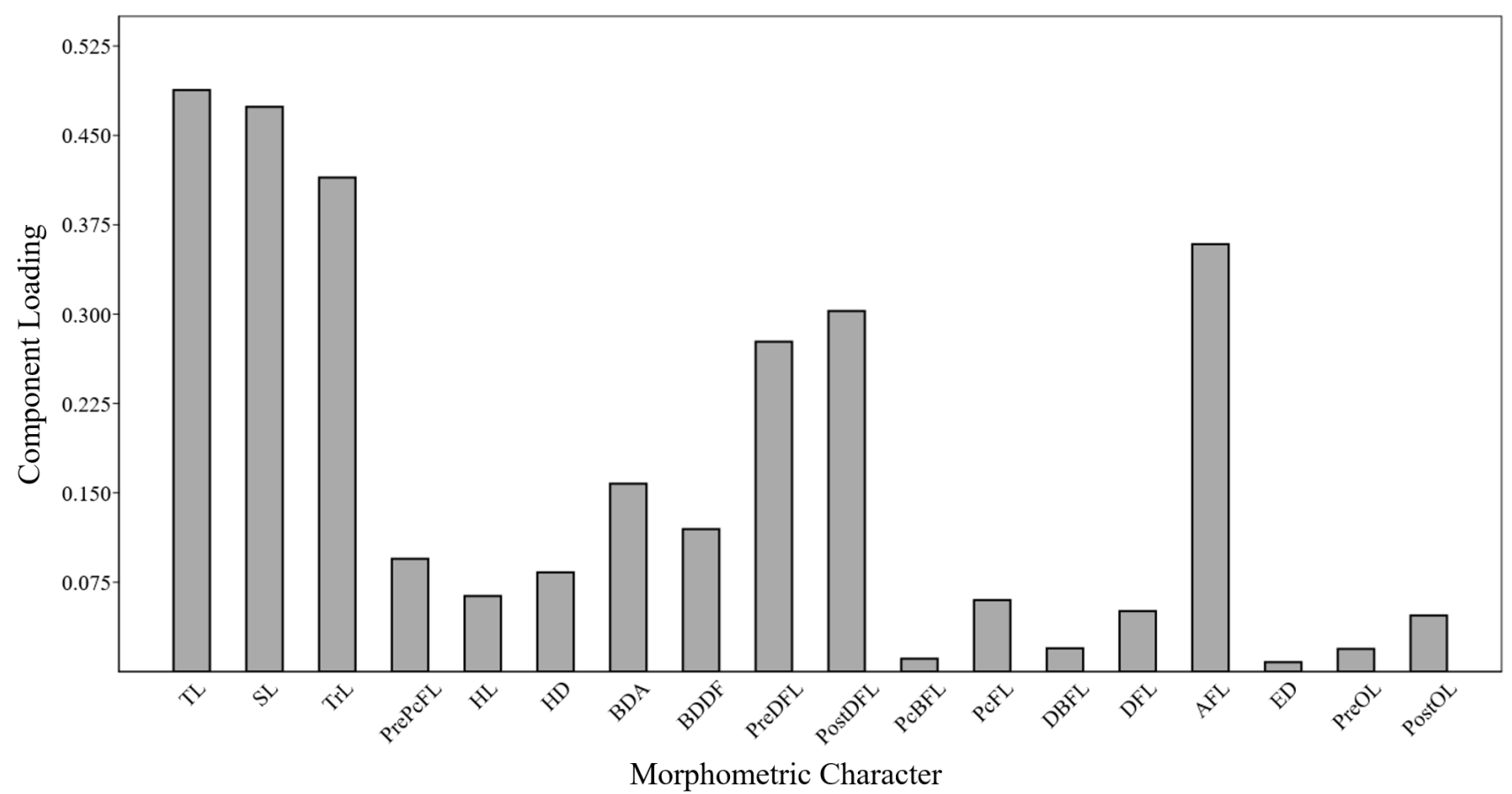

Figure 4. Component loadings in Principal Component 1 for size-adjusted metric characters obtained from male and female Chitala ornata from Laguna de Bay. 
families. They have found strong basis for Rensch's rule in families where males are typically larger than females, but no overall support for the rule in families with female-biased sexual size dimorphism. To further reinforce their conclusion, Webb \& Freckleton (2007) reviewed studies encompassing broad range of animal groups (including fish) and observed the same trend, proving that female-biased sexual size dimorphism consistently contradicted Rensch's rule.

Results showing female knifefish individuals growing larger than male agreed with other studies which established that in majority of fish species whose growth parameters were reported in FishBase, more than $80 \%$ of the female species grew faster and larger than their male counterparts, despite females having higher reproductive output or gonadal production (Pauly, 2019). It is mainly attributed in the disparity in the amount of 'energy' (i.e., ATP synthesized from food + oxygen) allocated by male and female fish for reproduction (Koch \& Wieser, 1983; Jonsson et al., 1991). Male fish individuals, aside from their production of gonadal products, expend additional energy in engaging fights to some extent with their conspecifics for the right to reproduce and in courting their potential mate (Pauly, 2019). Such behavior is generally absent in females resulting in females growing larger than males. Another reason for smaller males may be the influence of male hormone before and during spawning, which is known to increase the rate of metabolism and speed of swimming, thus leading to physical exhaustion of the males (Hoar, 1953).

The possible contributions of larger female fish to the survival of its species may be the reason for such disparity in size between knifefish sexes. It has been observed that from 28 stocks and species of bony fishes studied by Tsoukali et al. (2016), larger size in females allows higher fecundity. Beldade et al. (2012) also added that the influence of maternal phenotypic traits on the phenotype of offspring (Berkeley et al., 2004; Sato \& Suzuki, 2010) specifically to their size and survivability (Clark et al., 2005; Gagliano et al., 2007; Green, 2008; Barneche et al., 2018). Such characteristics are important in the establishment and proliferation of invasive fish population like that of the knifefish in Laguna de Bay (Grabowska \& Przybylski, 2015).

\section{Conclusions}

Differences between sexes of $C$. ornata from Laguna de Bay were observed in the present study. Females have larger genital papillae accompanied by a basal platform which was posited to aid in oviposition of eggs on the spawning substrate. Males on the other hand have a smaller blunt genital papilla. Multivariate analysis showed that sexual size dimorphism in knifefish was shown to be female-biased, wherein morphological characters are larger in females than males. Disparity in size was ascribed to the inherent difference in the contributions of the two sexes towards reproduction and in sizedependent advantages in quantity and quality of progenies.

\section{Acknowledgement}

Authors are grateful to Philippine Council for Agricultural, Aquatic and Natural Resources Research and Development Department of Science and Technology (PCAARRD-DOST) for funding this research endeavor and to the staff of University of the Philippines Los Baños - Limnological Station namely, Mrs. Beatriz M. Lontoc, Mr. Olivio Matalog, Mrs. Carmelita Alcasid, Mrs. Nenita B. Salvador, Mr. Reynaldo Matalog, and Mr. Randolf Gaffud for technical and administrative assistance.

All applicable international, national and/or institutional guidelines for the care and use of animals were followed.

\section{Literature Cited}

Andersson, M., 1994. Sexual Selection. Princeton, NJ, USA: Princeton University Press.

Barneche, D.R., D.R. Robertson, C.R. White \& D.J. Marshall, 2018. Fish reproductive-energy output increases disproportionately with body size. Science, 360: 642-645.

Beldade, R., S.J. Holbrook, R.J. Schmitt, S. Planes, D. Malone \& G. Bernardi, 2012. Larger female fish contribute disproportionately more to self-replenishment. Proceedings of the Royal Society B, Biological Sciences, 279: 21162121.

Berkeley, S., C. Chapman, \& S.M. Sogard, 2004. Maternal age as a determinant of larval growth and survival in a marine fish, Sebastes melanops. Ecology, 85: 1258-1264.

Brown-Peterson, N., D. Wyanski, F. Sacorido-Rey, B. Macewicz, \& S. Lowerre-Barbieri, 2011. A standardized terminology for describing reproductive development in fishes. Marine and Coastal Fisheries: Dynamics, Management, and Ecosystem Science, 3: 52-70.

Cagauan, A.G., 2007. Exotic aquatic species introduction in the Philippines for aquaculture - a threat to biodiversity or a boon to the economy? Journal of Environmental Science and Management, 10(1): 48-62.

Castro, J.M.C., M.V.C. Camacho, \& J.C.B. Gonzales. 2018. Reproductive biology of invasive knifefish (Chitala ornata) in Laguna de Bay, Philippines and its implications for control and management. Asian Journal of Conservation Biology, 7: 113-118.

Clark, D.L., J.M. Leis, A.C. Hay \& T. Trnski, 2005. Swimming 
ontogeny of larvae of four temperate marine fishes. Marine Ecology Progress Series, 292: 287-300.

Esmaeili, H.R., G. Sayyadzadeh \& M. Amini Chermahini, 2017. Sexual dimorphism in two catfish species, Mystus pelusius (Solander, 1794) and Glyptothorax silviae Coad, 1981 (Teleostei: Siluriformes). Turkish Journal of Zoology, 41: 144-149.

Gagliano, M., M.I. McCormick \& M.G. Meekan, 2007. Survival against the odds: ontogenetic changes in selective pressure mediate growth-mortality trade-offs in a marine fish. Proceedings of the Royal Society B, Biological Sciences, 274: 1575-1582.

Grabowska, J. \& M. Przybylski, 2015. Life-history traits of non -native freshwater fish invaders differentiate them from natives in the Central European bioregion. Reviews in Fish Biology and Fisheries, 25: 165-178.

Green, B.S., 2008. Maternal effects in fish populations. Advances in Marine Biology, 54: 1-105.

Hoar, W.S., 1953. Control and timing of fish migrations, Biological Reviews, 28: 437-452.

Jonsson, N., B. Jonsson \& L.P. Hansen, 1991. Energetic cost of spawning in male and female Atlantic salmon (Salmo salar L.). Journal of Fish Biology, 39: 739-744.

Koch, F. \& W. Wieser, 1983. Partitioning of energy in fish: can reduction of swimming activity compensate for the cost of production? Journal of Experimental Biology, 107: 141146.

Loppnow, G.L., K. Vascotto \& P.A. Venturelli, 2013. Invasive smallmouth bass (Micropterus dolomieu): history, impacts, and control. Management of Biological Invasions, 4(3): 191 $-206$.

Martin, Z. \& L. Page, 2015. Comparative morphology and evolution of genital papillae in a genus of darters (Percidae: Etheostoma). Copeia, 103(1): 99-124.

McGee, M.D. \& P.C. Wainwright, 2013. Sexual dimorphism in the feeding mechanism of three spine stickleback. Journal of Experimental Biology, 216: 835-840.

Pauly, D., 2019. Female fish grow bigger - let's deal with it. Trends in Ecology and Evolution, 34(3): 181-182.

Poulsen, A.F. \& J. Valbo-Jørgensen, eds. 2000. Fish Migrations and Spawning Habits in the Mekong Mainstream: A Survey Using Local Knowledge (Basinwide). AMFC Technical Report. Mekong River Commission, Vientiane. 149 pp.

Rensch, B., 1950. Die Abhängigkeit der relativen Sexualdifferenz von der Körpergrösse. Bonner Zoologische Beiträge, 1: 58-69.

Sato, T. \& N. Suzuki, 2010. Female size as a determinant of larval size, weight and survival period in the coconut crab, Birgus latro. Journal of Crustacean Biology, 30: 624-628.
Tsoukali, S., K.H. Olsson, A.W. Visser and B.R. MacKenzie, 2016. Adult lifetime reproductive value in fish depends on size and fecundity type. Canadian Journal of Fisheries and Aquatic Science, 73(9): 1405-1412.

Webb, T.J. \& R.P. Freckleton, 2007. Only half right: species with female-biased sexual size dimorphism consistently break Rensch's Rule. PLoS ONE, 2(9): e897. 